\title{
Comparative Evaluation of Midventral and Flank Laparotomy Approaches in Goat
}

\author{
A. A. Abubakar, ${ }^{1}$ R. A. Andeshi, ${ }^{1}$ A. S. Yakubu, ${ }^{1}$ F. M. Lawal, ${ }^{1}$ and U. Adamu ${ }^{2}$ \\ ${ }^{1}$ Department of Veterinary Surgery and Radiology, Usmanu Danfodiyo University, Sokoto 2346, Nigeria \\ ${ }^{2}$ Department of Theriogenology and Animal Production, Usmanu Danfodiyo University, Sokoto 2346, Nigeria
}

Correspondence should be addressed to A. A. Abubakar; babaji32002@gmail.com

Received 29 May 2014; Revised 21 July 2014; Accepted 21 July 2014; Published 24 August 2014

Academic Editor: Vito Laudadio

Copyright (C) 2014 A. A. Abubakar et al. This is an open access article distributed under the Creative Commons Attribution License, which permits unrestricted use, distribution, and reproduction in any medium, provided the original work is properly cited.

\begin{abstract}
The aim of the study was to compare two laparotomy approaches (flank and midventral). Ten $(n=10)$ apparently healthy goats of different breeds and sex, average age of $12 \pm 2.1$ months, and average weight of $13.4 \pm 2 \mathrm{~kg}$ were used for the investigation. The goats were randomly divided into flank and midventral groups, each group comprising five goats $(n=5)$. Standard aseptic laparotomy was performed under lumbosacral epidural anaesthesia with mild sedation. Postsurgical wound score showed significant difference $(P<0.05)$ in erythema at 18-24 hours and 10-14 days after surgery between the two approaches; significant difference of dehiscence between the two groups was also recorded at 10-14 days after surgery. Total white blood cells (WBC) and lymphocytes counts were significantly different $(P<0.05)$ at the first and second week after surgery. There was significant difference of platelets critical value and platelets dimension width at the first and second week after surgery. Significant difference of packed cells volume between the two approaches was also recorded one week after surgery. It was concluded that midventral laparotomy approach can be conveniently and safely performed under aseptic precautions without fear of intra- and postoperative clinical problems.
\end{abstract}

\section{Introduction}

Laparotomy in goat is an invasive surgical procedure into the abdominal cavity that allows visual examination of abdominal organs and documentation and correction of certain pathologic abnormalities observed $[1,2]$. Generally, it constitutes the single largest group of surgical operations carried out in ruminants $[3,4]$. Laparotomy is indicated for exploration of abdominal and pelvic cavities and other surgical procedures involving abdominal and pelvic organs; other specific indications are caesarean section, embryo transfer to produce transgenic goats, ovariectomy, rumenotomy, abomasotomy, ventral abdominal herniorrhaphy, intestinal resection, anastomosis, and cystotomy [5-11]. Two approaches (flank and midventral) have been recognized and are currently in use in both small and large animals surgery; however in ruminants flank approach is the most widely and frequently practiced $[1,2]$; due to the fact that surgical site can be visualized and observed from a distance and access healing, it was also reported to have reduced potential risk for evisceration if wound dehiscence is to occur, and the overlapping arrangement of the oblique muscles in the flank helps maintain the integrity of the abdominal wall if wound complication occurs [7].

The flank laparotomy approach is the most widely used among small ruminants surgeons for accessing abdominal and pelvic organs. However, the approach is associated with some challenges: animals tend to rub the surgical site during healing against available solid objects leading to loosening of sutures and subsequently formation of wound dehiscence, prolonged lateral recumbency in goats under anaesthesia is associated with decrease in rumen stasis thereby predisposing the animal to bloat and toxemic lactic acidosis, and the accessibility to the distant organs (far proximal or distal to the point of incision) is also limited [12]. We hypothesized that midventral laparotomy approach could be an alternative to flank laparotomy approach without much intra- and postsurgical complications. To test this hypothesis we compare the surgical wound assessment, intra- and postsurgical assessment, haematological profile, and subjective healing 
interval of the two laparotomy approaches. The aim of the study was to compare and evaluate flank and midventral laparotomy approaches in goats.

\section{Material and Methods}

Ten ( $n=10)$ apparently healthy goats free of any dermatological lesions with average age of $12 \pm 2.1$ months (mean \pm SD), male and female of different breeds, and average weight of $13.4 \pm 2$ kilograms (mean \pm SD) were used for the investigation. The goats were kept at the Usmanu Danfodiyo University Veterinary Teaching Hospital facilities and were conditioned for two weeks during which they were evaluated and stabilized for surgery. During evaluation serial blood sampling was done for comprehensive haematology to ascertain that the goats are fit for surgery and fecal sample was also collected to ascertain the intestinal worms burden. The goats were maintained on daily ration comprising wheat bran, bean husks, ground nut hay, and water ad libitum. The goats were randomly grouped into flank (FA) and midventral (MVA) approaches. Five $(n=5)$ goats were allocated to each group.

2.1. Surgical Procedure. Feed and water were withdrawn from animals at least 12 hours prior to the surgery. The left flank region of each goat in the FA group was prepared for routine aseptic surgery by clipping the hairs around the proposed surgical site; the site was scrubbed with Purit solution containing chlorhexidine gluconate B. P. 0.3\% W/V (Saro Lifecare Limited, Lagos, Nigeria) and rinsed with methylated spirit (Binji Pharmaceutical Company, Sokoto, Nigeria). Regional anesthesia was achieved with plain lignocaine hydrochloride and lignocaine injection B. P. 2\% (Sahib Singh Agencies, Mumbai, India) at $4 \mathrm{mg} \mathrm{kg}^{-1}$ through lumbosacral epidural anaesthesia as described by [13]. The epidural space was identified by loss of resistance to injection of $1 \mathrm{~mL}$ of air after piercing the ligamentum flavum. Mild sedation was achieved using xylazine 20 (xylazine $\mathrm{HCl} 20 \mathrm{mg} \mathrm{mL}^{-1}$, Kepro Holland) at $0.025 \mathrm{mg} \mathrm{kg}^{-1}$ intramuscular and atropine sulphate $0.6 \mathrm{mg} \mathrm{mL}^{-1}$ (Laborate Pharmaceuticals India) at $0.05 \mathrm{mg} \mathrm{kg}^{-1}$ intramuscular as vagolytic agent.

Goats in FA group were placed on right lateral recumbency exposing the left flank. Laparotomy was done according to standard procedure described by $[1,3,14]$. The laparotomy was routinely closed from within outward; muscle layers were closed using Becton chromic catgut of the size of $1 / 0$ and atraumatic $1 / 2$ circle taper point needle (Anhui Kangning Industrial Groups, China) using interrupted horizontal mattress suture pattern with simple interrupted reinforcement. The subcutaneous layer was closed using Becton chromic catgut of the size of $2 / 0$ and atraumatic $1 / 2$ circle taper point needle using simple continuous suture pattern. The skin was closed using Ford interlocking pattern with Agary nylon of the size of 0 and atraumatic 3/8 curved, cutting needle (Agary PharmaceuticalsLtd, Xinghuai, China). In MVA group, the cranial midventral area was prepared for aseptic procedure as described in FA group. Regional anesthesia was also achieved as described in FA group.
TABLE 1: Criteria used to score intraoperative and postsurgical complications.

\begin{tabular}{lccc}
\hline Outcome & & Scores & \\
& 0 & 1 & 2 \\
\hline Haemorrhage & None & Mild & Severe \\
Seroma & None & Mild & Severe \\
Wound fistula & None & Mild & Severe \\
Incisional hernia & None & Mild & Severe \\
\hline
\end{tabular}

Each animal was placed on dorsal recumbency exposing the midventral region. Laparotomy was done through linea alba in all female goats with little paramedian incision at the level of prepuce in all the males according to standard procedure described by $[1,3,4]$. The incision was closed routinely in three layers from within outward (linea alba, subcutaneous layer, and skin) with the same suture materials as described in FA group. The linea alba was closed using interrupted horizontal mattress pattern with simple interrupted reinforcement. 5\% acetaminophen injection $10 \mathrm{mg} \mathrm{kg}^{-1}$ intramuscular (Cadence Pharmaceutical Inc., Ireland) was administered for 3 days after surgery to take care of postoperative pain. Long acting $15 \%$ amoxicillin injection $20 \mathrm{mg} \mathrm{kg}^{-1}$ (Vetrimoxin) was administered once after surgery.

2.1.1. Surgical Wound Assessment. The clinical appearance of the skin was assessed and scored twice: 18-24 hours and 10-14 days after surgery as described by [15] using 4-point scoring scale, based on the following criteria: discharge, swelling, erythema, and dehiscence.

2.1.2. Haematology. Blood samples were collected from each animal in the two groups through the jugular vein after thorough disinfection of the area with methylated spirit; the sample was collected using $5 \mathrm{~mL}$ syringe and needle into EDTA bottles. The samples were collected before surgery as baseline, 18-24 hours after surgery, and subsequently on weekly interval till complete healing when sutures were removed. The samples were analyzed using digital automated haemoanalyser (Full Automated Blood Cell Counter PCE-210, Erma Inc., Tokyo, Japan) according to procedure described [16].

2.1.3. Intra- and Postoperative Complications. Intra- and postsurgical complications were assessed using 3-point scoring system designed by ourselves; parameters considered were intraoperative haemorrhages, postsurgical seroma, incisional hernia, and wound fistula (Table 1).

2.2. Subjective Healing Interval. Subjective healing interval was determined by visual observation and taking notes of days of apparent surgical site healing according to [17].

2.3. Statistical Analysis. Data generated from the four parameters (surgical wound scoring, haematology, surgical complications, and healing interval) were tabulated and mean and standard deviation were computed in each case. Student's 
TABLE 2: Postsurgical wound assessment score of flank and midventral approaches at $18-24$ hours and 10 days (mean \pm SD).

\begin{tabular}{lccc}
\hline \multirow{2}{*}{ Parameters } & Groups & $\begin{array}{c}\text { Scores } \\
\text { after surgery }\end{array}$ & $\begin{array}{c}10-14 \text { days after } \\
\text { surgery }\end{array}$ \\
\hline Discharge & FA & $0.80 \pm 0.45$ & $0.00 \pm 0.00$ \\
& MVA & $0.80 \pm 0.84$ & $0.00 \pm 0.00$ \\
Swelling & FA & $1.80 \pm 0.45$ & $0.50 \pm 0.56$ \\
& MVA & $2.00 \pm 0.00$ & $0.80 \pm 0.45$ \\
Erythema & FA & $1.40 \pm 0.55^{\mathrm{a}}$ & $0.25 \pm 0.50^{\mathrm{a}}$ \\
& MVA & $0.80 \pm 0.45^{\mathrm{b}}$ & $0.00 \pm 0.00^{\mathrm{b}}$ \\
Dehiscence & FA & $0.00 \pm 0.00$ & $0.25 \pm 0.50^{\mathrm{a}}$ \\
& MVA & $0.00 \pm 0.00$ & $0.00 \pm 0.00^{\mathrm{b}}$ \\
\hline
\end{tabular}

${ }^{\mathrm{ab}}$ Pair of means bearing different superscript are significantly different $(P<$ $0.05)$.

$t$-test was used to compare statistical significant difference between the flank and midventral variables of each parameter at 95\% confident interval using GraphPad Instat Statistical software package 2010. $T$ value was considered significant when $P$ value is less than 0.05 .

\section{Results}

3.1. Postsurgical Wound Assessment. At 18-24 hours after surgery, there was serous discharge in all groups; the mean discharge scores were $(0.80 \pm 0.45$ and $0.80 \pm 0.84)$ for flank and midventral approaches, respectively. There was no significant difference between the two groups when compared. At 10-14 days after surgery, there was no discharge observed (Table 2).

Midventral group had higher swelling score $(2.00 \pm 00)$ in comparison with flank approach $(1.8 \pm 0.45)$ and the overall swelling score was higher at 18-24 hours after surgery compared to $10-14$ days after surgery $(0.50 \pm 0.56$ and $0.80 \pm$ 0.45 ) in flank and midventral, respectively (Table 2). There was no significant difference between flank and midventral approach both at 18-24 hrs and at 10-14 days after surgery.

The flank approach at 18-24 hours had higher erythema score $(1.40 \pm 0.55)$ when compared with midventral group $(0.80 \pm 0.45)$ and there was significant difference $(P<0.05)$ of erythema between the two approaches (Table 2). At 10-14 days after surgery, flank approach had higher erythema score $(0.25 \pm 0.50)$ while midventral approach had no erythema record and there was significant difference $(P<0.05)$ between the two approaches.

Dehiscence was not recorded at 18-24 hours after surgery in all the groups; however, at 10-14 days after surgery dehiscence was observed in flank approach with significant difference $(P<0.05)$ between the two groups (Table 2$)$.

3.2. Intra- and Postsurgical Complications. Intraoperative haemorrhage score was higher in flank approach $(1.4 \pm 0.55)$ when compared with midventral approach $(1.00 \pm 0.70)$; there was no significant difference $(P>0.05)$ between the two groups (Table 3 ). There were no postoperative complications of incisional hernia, seroma, and wound fistula recorded.
TABLE 3: Intra- and postsurgical complications scores of flank and midventral approaches (mean $\pm \mathrm{SD}$ ).

\begin{tabular}{lcc}
\hline Parameters & Groups & Scores \\
\hline Intraoperative complication & & \\
Haemorrhage & FA & $1.40 \pm 0.55$ \\
Postoperative complications & MVA & $1.00 \pm 0.70$ \\
\multicolumn{1}{c}{ Incisional hernia } & FA & $0.00 \pm 0.00$ \\
Seroma & FVA & $0.00 \pm 0.00$ \\
& FA & $0.00 \pm 0.00$ \\
Wound fistula & FA & $0.00 \pm 0.00$ \\
& MVA & $0.00 \pm 0.00$ \\
& & $0.00 \pm 0.00$ \\
\hline
\end{tabular}

There is no significant difference $(P>0.05)$.

3.3. Haematological Profiles. There were variations of total white blood cells (WBC) count of the two approaches before surgery, at 18-24 hours, and at the first and second week after surgery; the midventral group had higher WBC value at all the intervals with significant differences $(P<0.05)$ at first and second week after surgery (Table 4 ). There were slight variations of total granulocytes between the two groups with the midventral group having the higher values at all the intervals, but there is no significant difference between the two groups (Table 4). The lymphocytes values of the two groups also varied and the midventral approache had the highest value. There were significant differences $(P<0.05)$ recorded between the two approaches at first and second week interval: $21.33 \pm 8.22$ flank approach against $28.32 \pm$ 11.98 midventral approach and $15.20 \pm 3.52$ flank approach against $25.48 \pm 6.00$ midventral approach (Table 4 ). There were also slight variations of monocytes values between the flank and midventral approaches at different timing interval; the midventral had higher values when compared with flank approach but there were no significant differences between the two approaches at any given time interval (Table 4).

The values of the platelets varied slightly between the two approaches, with the midventral approach having a higher value when compared with flank approach, and there was no significant difference between the two approaches at all the timing intervals (Table 5). The platelets critical values varied between the two approaches with the midventral having the higher values; there was significant difference $(P<0.05)$ at second week interval between the flank and midventral approach $(0.15 \pm 0.04$ against $0.25 \pm 0.08)$, respectively (Table 5 ). The mean platelets volumes also showed slight variations between the two groups, but there was no significant difference between the groups at any of the timing intervals; the midventral approach had higher values when compared with the flank approach (Table 5). The platelets dimension width values were slightly higher in midventral approach compared to flank approach and a significant difference $(P<$ 0.05) was recorded between the two approaches at 18-24hour interval (Table 5).

The packed cells volume of the two approaches showed slight variations with the midventral approach having the 
TABLE 4: Total leucocytes and differential leucocytes counts before and after surgery of the flank and midventral approaches (mean \pm SD).

\begin{tabular}{lccccc}
\hline \multirow{2}{*}{ Parameters } & \multirow{2}{*}{ Groups } & & \multicolumn{3}{c}{ Mean scores } \\
& & Before surgery & 18-24 hrs after surgery & One week after surgery & Two weeks after surgery \\
\hline \multirow{2}{*}{ Total WBC $\left(\times 10^{3} / \mu \ell\right)$} & FA & $25.48 \pm 4.19$ & $37.70 \pm 3.90$ & $34.93 \pm 3.12^{\mathrm{a}}$ & $32.98 \pm 5.28^{\mathrm{a}}$ \\
& MVA & $33.86 \pm 9.96$ & $50.52 \pm 16.32$ & $51.08 \pm 5.07^{\mathrm{b}}$ & $45.62 \pm 6.85^{\mathrm{b}}$ \\
Granulocytes $\left(\times 10^{3} / \mu \ell\right)$ & FA & $11.10 \pm 3.69$ & $13.24 \pm 3.45$ & $10.23 \pm 5.72$ & $13.85 \pm 5.33$ \\
& MVA & $11.38 \pm 4.41$ & $20.90 \pm 10.51$ & $18.62 \pm 5.07$ & $15.06 \pm 3.52$ \\
Lymphocytes $\left(\times 10^{3} / \mu \ell\right)$ & FA & $11.74 \pm 3.27$ & $19.16 \pm 2.61$ & $28.33 \pm 8.22^{\mathrm{a}}$ & $15.20 \pm 5.05^{\mathrm{a}}$ \\
Monocytes $\left(\times 10^{3} / \mu \ell\right)$ & FA & $33.86 \pm 3.40$ & $24.06 \pm 7.37$ & $3.35 \pm 0.66$ & $25.48 \pm 6.00^{\mathrm{b}}$ \\
& MVA & $4.14 \pm 1.02$ & $5.08 \pm 1.21$ & $4.12 \pm 0.44$ & $3.88 \pm 0.66$ \\
\hline
\end{tabular}

${ }^{\mathrm{ab}}$ Pair of means bearing different superscript are significantly different $(P<0.05)$.

TABle 5: Platelet characteristics before and after surgery of the two approaches (mean \pm SD).

\begin{tabular}{lccccc}
\hline \multirow{2}{*}{ Parameters } & \multirow{2}{*}{ Groups } & \multicolumn{3}{c}{ Mean scores } \\
& & Before surgery & $18-24$ hrs after surgery & One week after surgery & Two weeks after surgery \\
\hline \multirow{2}{*}{ Platelets $\left(\times 10^{3} / \mu \ell\right)$} & FA & $287.20 \pm 123.58$ & $375.60 \pm 99.58$ & $369.95 \pm 144.66$ & $269.75 \pm 128.18$ \\
& MVA & $351.40 \pm 75.20$ & $416.60 \pm 94.88$ & $376.20 \pm 90.78$ & $444.40 \pm 149.93$ \\
Platelets critical value $(\%)$ & FA & $0.16 \pm 0.07$ & $0.21 \pm 0.06$ & $0.21 \pm 0.08$ & $0.15 \pm 0.04^{\mathrm{a}}$ \\
& MVA & $0.20 \pm 0.04$ & $0.24 \pm 0.05$ & $0.22 \pm 0.03$ & $0.25 \pm 0.08^{\mathrm{b}}$ \\
Mean platelets volume $(\mathrm{fl})$ & FA & $5.60 \pm 0.14$ & $5.68 \pm 0.22$ & $5.60 \pm 0.09$ & $5.55 \pm 0.24$ \\
& MVA & $5.72 \pm 0.09$ & $5.74 \pm 0.08$ & $5.72 \pm 0.22$ & $5.68 \pm 0.13$ \\
Platelets dimension width $(\mathrm{fl})$ & FA & $683.90 \pm 0.37$ & $684.80 \pm 0.29^{\mathrm{a}}$ & $684.30 \pm 0.05$ & $684.30 \pm 0.47$ \\
& MVA & $684.26 \pm 0.13$ & $684.22 \pm 0.20^{\mathrm{b}}$ & $684.2 \pm 0.18$ & $684.12 \pm 0.18$ \\
\hline
\end{tabular}

${ }^{\mathrm{ab}}$ Pair of means bearing different superscript are significantly different $(P<0.05)$.

higher PCV values when compared with the flank approach. There was significant difference $(P<0.05)$ recorded at one week interval between the two approaches (Table 6). There were no significant differences $(P>0.05)$ between the two approaches in all other erythrocytic indices (red blood cells count, haemoglobin, mean corpuscular volume, mean corpuscular haemoglobin, mean corpuscular haemoglobin concentration, and red blood cells distribution width). However, the values of midventral approach are higher at different timing intervals in all other erythrocytic indices (Table 6).

3.4. Subjective Healing Interval. The mean subjective healing intervals were $13.0 \pm 1.14$ and $12.4 \pm 0.5$ for flank and midventral approach. Midventral approach had lower mean healing intervals in days compared to the flank approach. There was no significant difference $(P=0.643)$ between the two groups when compared (Figure 1).

\section{Discussions}

Laparotomy is commonly indicated either for exploratory purposes when clinical diagnosis is uncertain or for therapeutic surgical intervention when specific diagnosis has been made [2]. Flank approach is the most commonly practiced technique among large animal surgeons with the animal under local anaesthesia [18]. Ventral paramedian or midventral laparotomy approach is an alternative practice by few large animal surgeons that necessitates the animal

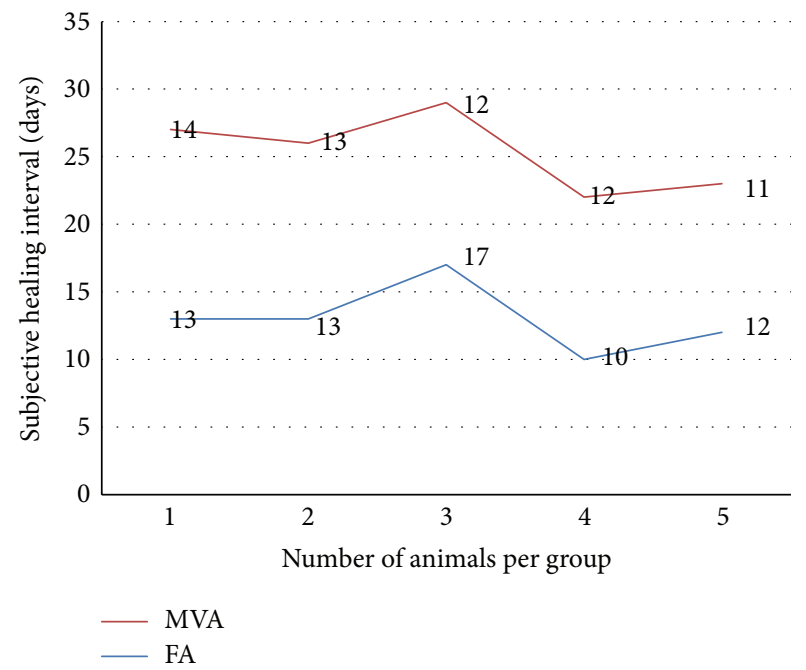

FIGURE 1: Subjective healing interval (days) of the animals flank (FA) and midventral (MVA) approaches.

placement in dorsal recumbency. The two main indications in bovine are ventral abomasopexy and cesarean section, in which it offers advantages in the delivery of oversized or emphysematous fetuses and in complicated deliveries, including uterine tears $[12,19]$.

Surgical wound assessment showed significant difference of erythema both at 18-24 and at 10-14 days after surgery 
TABLE 6: Erythrocytic indices before and after surgery of the two approaches (mean \pm SD).

\begin{tabular}{|c|c|c|c|c|c|}
\hline \multirow{2}{*}{ Parameters } & \multirow{2}{*}{ Groups } & \multicolumn{4}{|c|}{ Mean scores } \\
\hline & & Before surgery & 18-24 hrs after surgery & One week after surgery & Two weeks after surgery \\
\hline \multirow{2}{*}{$\operatorname{RBC}\left(\times 10^{6} / \mu \ell\right)$} & FA & $12.32 \pm 1.35$ & $12.79 \pm 1.23$ & $12.23 \pm 1.32$ & $12.10 \pm 2.07$ \\
\hline & MVA & $13.13 \pm 0.51$ & $13.69 \pm 0.52$ & $13.36 \pm 0.85$ & $13.03 \pm 1.05$ \\
\hline \multirow{2}{*}{$\operatorname{PCV}(\%)$} & FA & $21.92 \pm 2.56$ & $24.66 \pm 5.24$ & $16.15 \pm 2.85^{\mathrm{a}}$ & $22.75 \pm 5.98$ \\
\hline & MVA & $25.22 \pm 1.19$ & $25.90 \pm 1.15$ & $25.72 \pm 4.37^{\mathrm{b}}$ & $23.84 \pm 3.07$ \\
\hline \multirow{2}{*}{ Haemoglobin (g/d) } & FA & $8.12 \pm 1.36$ & $8.98 \pm 2.25$ & $8.63 \pm 1.51$ & $8.68 \pm 2.19$ \\
\hline & MVA & $9.16 \pm 0.43$ & $9.84 \pm 0.59$ & $9.86 \pm 1.28$ & $9.30 \pm 1.36$ \\
\hline \multirow{2}{*}{ Mean corpuscular volume $(f \ell)$} & FA & $17.72 \pm 2.56$ & $19.08 \pm 2.37$ & $17.58 \pm 0.88$ & $18.58 \pm 1.98$ \\
\hline & MVA & $19.10 \pm 2.09$ & $18.06 \pm 0.57$ & $14.10 \pm 2.09$ & $18.20 \pm 1.13$ \\
\hline \multirow{2}{*}{ Mean corpuscular haemoglobin (pg) } & FA & $6.50 \pm 0.42$ & $6.88 \pm 0.95$ & $6.78 \pm 0.50$ & $7.00 \pm 1.13$ \\
\hline & MVA & $6.92 \pm 0.04$ & $7.13 \pm 0.26$ & $7.37 \pm 0.61$ & $7.04 \pm 0.48$ \\
\hline \multirow{2}{*}{ Mean corpuscular haemoglobin con. (g/L) } & $\mathrm{FA}$ & $36.80 \pm 2.16$ & $36.26 \pm 3.50$ & $38.5 \pm 1.94$ & $37.36 \pm 2.18$ \\
\hline & MVA & $36.32 \pm 1.91$ & $37.96 \pm 1.90$ & $38.58 \pm 3.12$ & $38.94 \pm 1.82$ \\
\hline \multirow{2}{*}{ RBC distribution width (\%) } & FA & $30.18 \pm 4.71$ & $32.00 \pm 4.37$ & $30.98 \pm 4.86$ & $29.80 \pm 6.19$ \\
\hline & MVA & $32.18 \pm 1.26$ & $34.48 \pm 1.96$ & $33.40 \pm 2.23$ & $32.92 \pm 2.72$ \\
\hline
\end{tabular}

${ }^{\mathrm{ab}}$ Pair of means bearing different superscript are significantly different $(P<0.05)$.

with flank approach having the highest erythema score and this could be due to surgical trauma elucidated by the traumatic surgical instruments on the soft tissue in the course of surgery; this is because the flank region has three layers of abdominal muscles that have to be passed through before getting access into the abdominal cavity in comparison with midventral approach through linea alba aponeurosis (ligament) which is passed through before gaining access to abdominal cavity; the ligament poorly responds to pressure of traumatic surgical instruments which brought about the less erythematous response. The high erythema score recorded in flank approach could also be a result of abdominal muscles tissue response to absorbable suture materials used for apposing the muscles mass which is more bulky than that of midventral approach. The overall scoring showed higher erythema earlier before surgery at 18-24 hours and this finding is consistent with the studies conducted by $[15$, 17] where significant differences among the variables were observed.

Dehiscence was also observed in the flank approach at 10-14 days after surgery with significant difference when compared with midventral approach; this could be a result of scratching the surgical site (flank) with available objects in the pen as a result of tissue irritation in the course of healing process. It could also be due to self-mutation with horn of hind limbs in response to tissue irritation. Dehiscence score was by far less in midventral approach due to lesser chances of scratching and self-mutilation around the region. Our finding was contrary to that of [15], which recorded no dehiscence in a similar study using canine species, and that of [17], which recorded mild dehiscence both at 18-24 hours and at 1014 day after surgery but without significant difference in a similar study using caprine species.

The intraoperative hemorrhage score recorded was higher in the flank approach compared with the midventral approach, though without significant difference; this could be a result of high vascular channels available in the abdominal muscle mass when compared to poor vasculatures associated with tendons and ligament in the linea alba. This could serve as one of the advantages of midventral approach particularly when dealing with nonelective laparotomy in which the patient hematocrit reading is below normal range. The packed cell volume (PCV) of the flank approach decreased significantly one week after surgery when compared with midventral approach; this could be due to high intraoperative hemorrhage recorded. This finding was in line with the finding of $[20,21]$, both in a study involving laparotomy with goat; they noted that remarkable hematocrit decreased after surgery with significant difference. [8] also reported significant decrease in PCV in postoperative abdominal surgery in bovine.

Higher values of total white blood cells count and lymphocytes count were recorded in midventral approach at the second week after surgery with significant difference when compared with the flank approach and this could be attributed to high persistent chronic inflammatory response in the course of tissue repair or it could be due to surgical stress because midventral approach is more stressful in relation to surgical positioning than lateral recumbency. Our finding is also in line with those of $[20,21]$ who also recoded elevated values leukocytes count. But [8] noticed an average total leukocytes value within normal physiologic range after abdominal surgery in dairy cows. Percentage platelets critical value recorded was higher in midventral approach; this could be due to lesser whole blood loss observed intraoperatively as decrease in whole total blood volume leads to gross interference of the different components of the blood cells including platelets. This may also serve as an advantage in midventral approach because the higher the platelets critical values, the quicker the chances of blood clotting response.

There were slight variations of means subjective healing interval of the two approaches but without significant difference $(P=0.643)$, with the flank approach having higher means number of days $(13 \pm 1.14)$ to complete surgical 
wound healing when compared with $12.4 \pm 0.5$ mean days for midventral approach. The slight variation of days of healing interval might be due to surgical site interference with the object coming contact with the surgical wound as reported by $[22,23]$, as the chance of surgical site contact with surrounding object is higher in flank laparotomy site compared to midventral site. The variation could also be a result of other local factors that affect wound healing like oxygenation, foreign body contact with the surgical wound, and venous insufficiency as reported by [23].

\section{Conclusion}

It was concluded that the midventral laparotomy approach can be safely and conveniently performed without fear of clinical complications in goats. When correctly performed, it will offer less intraoperative hemorrhage and postoperative tissue reactions.

We recommend the use of midventral laparotomy approach for routine abdominal surgery in goats as an alternative to flank approach. Further study on pregnant goats to see whether midventral abdominal incisional closure can withstand pressure of gravid uterus also needs to be conducted.

\section{Conflict of Interests}

The authors declare that there is no conflict of interests regarding the publication of this paper.

\section{Acknowledgments}

The authors appreciate the effort of Mallam Bello Kaura of haematology laboratory, college of health sciences, for processing the blood samples. They also appreciate the effort of technical staff too numerous to mention in large animal surgery of Veterinary Teaching Hospital, Usmanu Danfodiyo University, Sokoto.

\section{References}

[1] N. K. Ames, Noordsy's Food Animal Surgery, Wiley-Blackwell, 5th edition, 2007.

[2] D. A. Hendrickson, Techniques in Large Animal Surgery, Blackwell Publishing, Ames, Iowa USA, 3rd edition, 2007.

[3] D. E. Freeman, Abdominal Surgery: Summary Procedure and Principles, International Veterinary Information Service, New York, NY, USA, 2003.

[4] S. R. R. Haskell, "Surgery of the sheep and goat digestive system," in Farm Animal Surgery, S. L. Fublin and N. G. Ducharme, Eds., pp. 521-526, Saunders an Imprint of Elservier, 2004.

[5] S. N. Dehghani and A. M. Ghadrdani, "Bovine rumenotomy: comparison of four surgical techniques," The Canadian Veterinary Journal, vol. 36, no. 11, pp. 693-697, 1995.

[6] M. Thibier and B. Guérin, "Embryo transfer in small ruminants: the method of choice for health control in germplasm exchanges," Livestock Production Science, vol. 62, no. 3, pp. 253270,2000 .
[7] D. C. van Metre, J. W. Tyler, and S. M. Stehman, "Diagnosis of enteric disease in small ruminants.," The Veterinary Clinics of North America: Food Animal Practice, vol. 16, no. 1, pp. 87-115, 2000.

[8] K. Nuss, B. Lejeune, C. Lischer, and U. Braun, "Ileal impaction in 22 cows," Veterinary Journal, vol. 171, no. 3, pp. 456-461, 2006.

[9] F. A. Al-Sobayil and A. F. Ahmed, "Surgical treatment for different forms of hernias in sheep and goats," Journal of Veterinary Science, vol. 8, no. 2, pp. 185-191, 2007.

[10] T. S. Sang, K. J. Sung, S. Y. Hong et al., "Laparoscopy versus laparotomy for embryo transfer to produce transgenic goats (Capra hircus)," Journal of Veterinary Science, vol. 9, no. 1, pp. 103-107, 2008.

[11] P. P. M. Teixeira, L. C. Padilha, T. F. Motheo et al., "Ovariectomy by laparotomy, a video-assisted approach or a complete laparoscopic technique in Santa Ines sheep," Small Ruminant Research, vol. 99, no. 2-3, pp. 199-202, 2011.

[12] L. G. Schultz, J. W. Tyler, H. D. Moll, and G. M. Constantinescu, "Surgical approaches for cesarean section in cattle," Canadian Veterinary Journal, vol. 49, no. 6, pp. 565-568, 2008.

[13] A. B. Sadegh, Z. Shafiei, and S. D. Nazhvani, "Comparison of epidural anesthesia with lidocaine-distilled water and lidocaine-magnesium sulfate mixture in goat," Veterinarski Arhiv, vol. 79, no. 1, pp. 11-17, 2009.

[14] R. P. S. Tuagi and S. Jit, "Ruminant surgery," in Textbook of the Surgical Disease of Cattle, Buffaloes, Camels, Sheep and Goats, pp. 195-223, C.S.B Publishers and Distributors, New Delhi, India, 1993.

[15] A. Sylvestre, J. Wilson, and J. Hare, "A comparison of 2 different suture patterns for skin closure of canine ovariohysterectomy," Canadian Veterinary Journal, vol. 43, no. 9, pp. 699-702, 2002.

[16] D. J. Weiss, "Application of flow cytometric techniques to veterinary clinical hematology," Veterinary Clinical Pathology, vol. 31, no. 2, pp. 72-82, 2002.

[17] A. A. Abubakar, J. B. Adeyanju, R. O. C. Kene et al., "Evaluation of three suture techniques based on surgical wound assessment in Caprine," Scientific Journal of Veterinary Advances, vol. 1, no. 4, pp. 101-104, 2012.

[18] P. Mulon and A. Desrochers, "Surgical abdomen of the calf," Veterinary Clinics of North America-Food Animal Practice, vol. 21, no. 1, pp. 101-132, 2005.

[19] Z. B. Ismail, A. Al-Majali, and K. Al-Qudah, "Clinical and surgical findings and outcome following rumenotomy in adult dairy cattle affected with recurrent rumen tympany associated with non-metallic foreign bodies," The American Journal of Animal and Veterinary Sciences, vol. 2, no. 3, pp. 66-71, 2007.

[20] A. Mohammed, I. O. Igbokwe, and H. Abdul, "Observations on the proximal duodenal obstruction in Borno White goats," Small Ruminant Research, vol. 12, no. 2, pp. 185-192, 1993.

[21] L. O. Aka, R. I. Obiadike, C. A. Eze, and C. O. Igbokwe, "Physiological evidence of good tolerance of concurrent rumen fistlation and duodenal cannulation in West African Dwarf Sheep," Animal Research International, vol. 6, no. 2, pp. 1019-1027, 2009.

[22] J. L. Burns, J. S. Mancoll, and L. G. Phillips, "Impairments to wound healing," Clinics in Plastic Surgery, vol. 30, no. 1, pp. 4756, 2003.

[23] S. Guo and L. A. DiPietro, "Factors affecting wound healing," Journal of Dental Research, vol. 89, no. 3, pp. 219-229, 2010. 

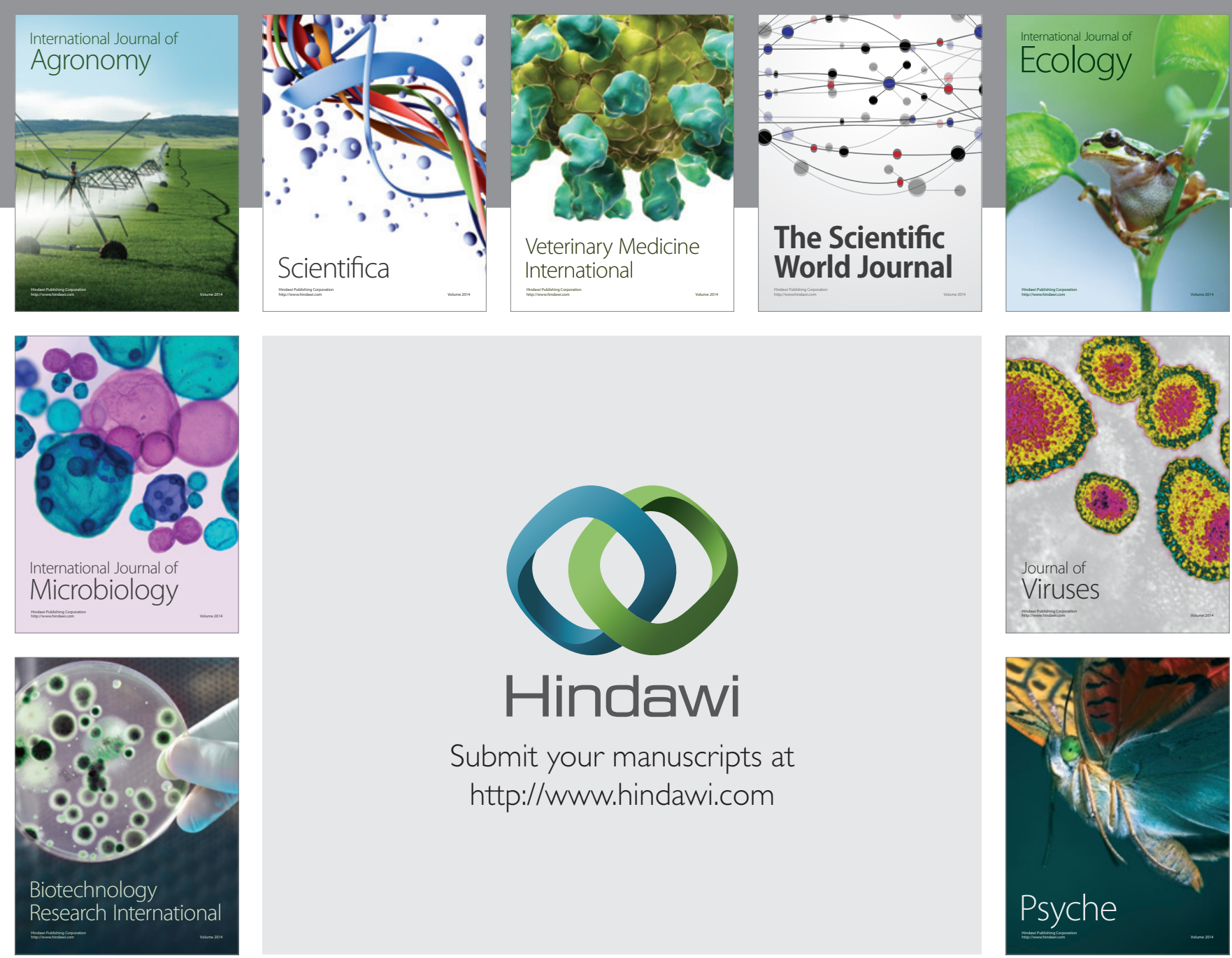

Submit your manuscripts at http://www.hindawi.com
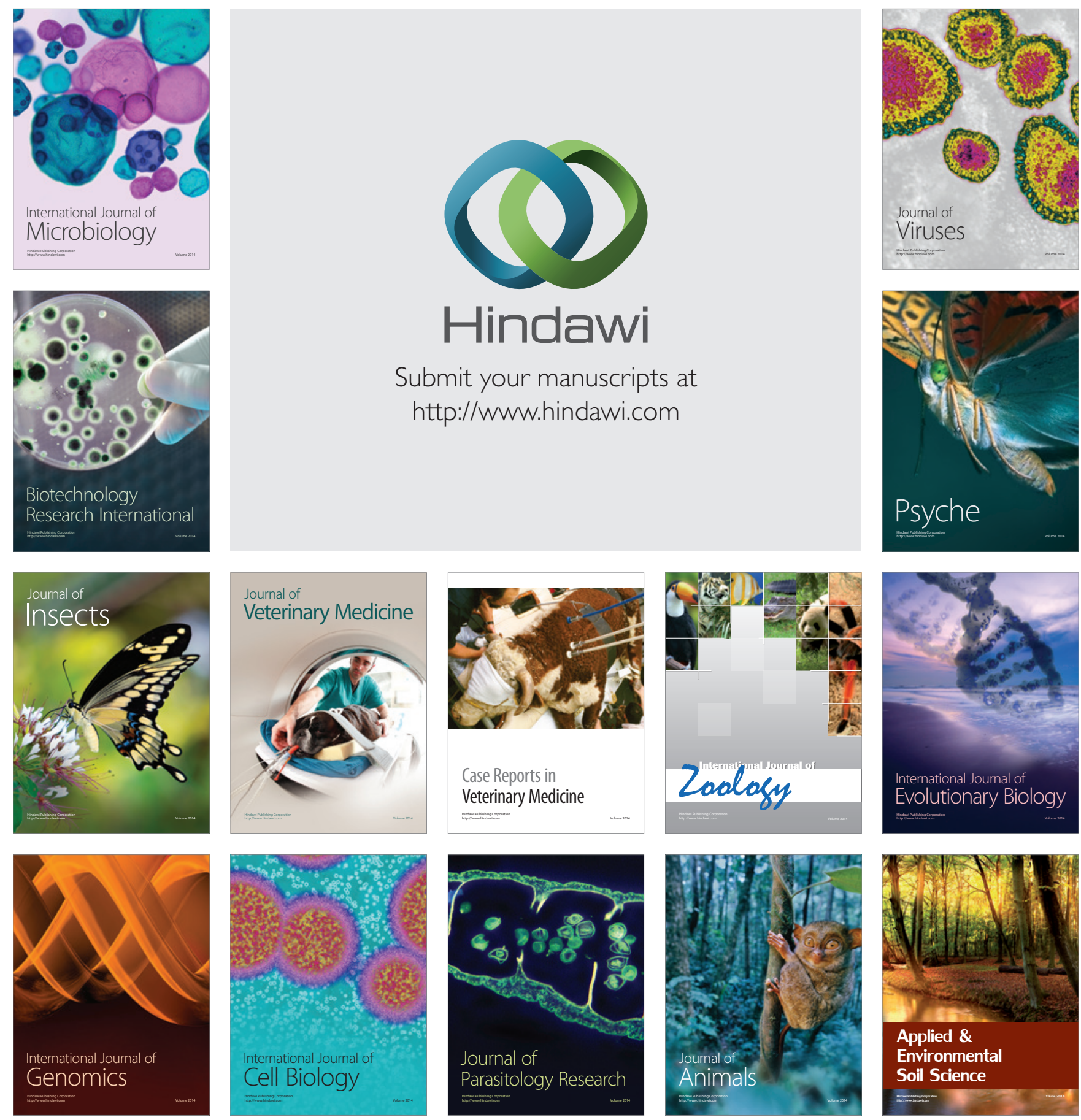